\title{
MICROSPOTS ON IIIa- EMULSIONS: NEW RESULTS
}

\author{
S.B. TRITTON, D.H. MORGAN and M.R. CRANSTON \\ Royal Observatory \\ Blackford Hill \\ Edinburgh EH9 $3 \mathrm{HJ}$ \\ U.K.
}

SUMMARY: This paper continues the investigations carried out at the Royal Observatory Edinburgh into the microspot problem affecting Kodak Spectroscopic plates taken with the UK $1.2 \mathrm{~m}$ Schmidt Telescope (UKST) at Siding Spring Observatory (SSO). Over 10,000 plate inspections have been made since the previous report. Analysis of all the available data shows that UKST plates on IIIa- emulsions processed up to January 1991 continue to show evidence of microspot contamination. Various changes to the processing procedures are listed and the effects on spot formation are analyzed. The effectiveness of Rapid Selenium Toner in the original processing line and post-processing is discussed.

\section{Appearance of Microspots}

Until 1990, microspots were mainly identified by checking the emulsion of plates in reflected light. Spots appeared like little mirrors and, in transmitted light, these spots appeared gold. During the 1990 checks many plates were noticed to be affected by non-reflective spots which appear more yellow than gold (Tritton, Morgan \& Cranston [TMC] 1992, and references therein).

\section{Processing Diary at SSO}

Table 1 lists changes in plate processing at SSO since June 1982 when the single processing line was replaced by two lines. It updates the table given by TMC; in particular, the introduction of potassium iodide into the processing line in early 1991 should be noted.

\section{Microspot Statistics}

Tables 2 and 3 detail the number of plates affected by microspots; the time division mainly follows changes in the processing procedures detailed in Table 1. The results are also shown graphically in Fig. 1. 
Table 1. Processing Diary at SSO from June 1982

\begin{tabular}{|c|c|c|}
\hline Date & Plate & Change in Processing \\
\hline 10 Jun 1982 & I 7793 & $\begin{array}{l}\text { 'Line A' introduced for IIIa- emulsions (Rapid Fix + } 45 \text { mins } \\
\text { wash, no Hypoclear) } \\
\text { 'Line B' for other emulsions (Ordinary Fix + brief wash + } \\
\text { Hypoclear + } 45 \text { mins wash) }\end{array}$ \\
\hline 23 Nov 1983 & VR 8917 & $\begin{array}{l}\text { RST (1:39) introduced to 'Line A' (Rapid Fix + } 5 \text { mins wash + } \\
5 \text { mins RST* + } 10 \text { mins wash) } \\
\text { Changes in wash times to 'Line B' (Ordinary Fix + } 5 \text { mins } \\
\text { wash + Hypoclear + } 10 \text { mins wash) }\end{array}$ \\
\hline 3 Jul 1984 & B 9444 & RST suspended (in 'Line A') \\
\hline 2 May 1986 & V 11085 & $\begin{array}{l}\text { Rapid Fix introduced into 'Line B' (Ordinary Fix }+5 \text { mins } \\
\text { wash + Hypoclear }+45 \text { mins wash) } \\
\text { Two lines maintained to keep IIIa- emulsions separate }\end{array}$ \\
\hline 19 Mar 1991 & OR 14218 & RST resumed for selected plates processed in 'Line $A$ ' \\
\hline 21 Mar 1991 & U 14229 & $0.2 \mathrm{~g} / \mathrm{KI}$ added to Rapid Fix in 'Line $\mathrm{B}$ ' \\
\hline 29 Apr 1991 & OR 14328 & $0.2 \mathrm{~g} / \mathrm{KI}$ added to Rapid Fix in 'Line $\mathrm{A}$ ' \\
\hline
\end{tabular}

*RST = Kodak Rapid Selenium Toner

Table 2. Checks made between January 1990 and August 1993 on IIIa-J emulsions

\begin{tabular}{c|r|c|c|c|c|c|c}
\hline \multirow{2}{*}{ Line } & \multirow{2}{*}{ Plate Numbers } & \multicolumn{6}{|c}{ Number of Plates } \\
\cline { 3 - 8 } & & Spot free & A+B & C & D+E+F & Total & \%Spotted \\
\hline \hline A & $1-5999$ & 1179 & 343 & 195 & 230 & 1947 & 39 \\
\hline A & $6000-7992$ & 234 & 76 & 6 & 3 & 319 & 26 \\
\hline A & $7793-8916$ & 316 & 6 & 12 & 3 & 337 & 6 \\
B & $7793-8916$ & 1 & 11 & 0 & 0 & 12 & 91 \\
\hline A & $8917-9444$ & 60 & 0 & 0 & 0 & 60 & 0 \\
B & $8917-9444$ & 3 & 11 & 0 & 0 & 14 & 78 \\
\hline A & $9445-11085$ & 254 & 30 & 16 & 13 & 313 & 18 \\
B & $9445-11085$ & 26 & 17 & 0 & 0 & 43 & 39 \\
\hline A & $11086-12999$ & 127 & 6 & 5 & 7 & 145 & 12 \\
B & $11086-12999$ & 12 & 6 & 1 & 0 & 19 & 36 \\
\hline A\&B & $13000-14218$ & 30 & 5 & 0 & 0 & 35 & 14 \\
\hline
\end{tabular}

Note: The 'grade' of microspot contamination gives an indication of the severity. Plates graded A and B show spots in calibration areas and/or plate label only. Plates graded C-F show increasing levels of microspot contamination in the sky area. 
Table 3: Checks made between January 1990 and August 1993 on IIIa-F emulsions

\begin{tabular}{c|r|c|c|c|c|c|c}
\hline \multirow{2}{*}{ Line } & \multirow{2}{*}{ Plate Numbers } & \multicolumn{6}{|c}{ Number of Plates } \\
\cline { 3 - 8 } & & Spot free & A+B & C & D+E+F & Total & \%Spotted \\
\hline \hline A & $1-5999$ & 225 & 57 & 32 & 20 & 334 & 32 \\
\hline A & $6000-7992$ & 117 & 75 & 15 & 0 & 207 & 43 \\
\hline A & $7793-8916$ & 62 & 1 & 4 & 1 & 68 & 8 \\
B & $7793-8916$ & 2 & 7 & 3 & 0 & 12 & 83 \\
\hline A & $8917-9444$ & 35 & 0 & 0 & 0 & 35 & 0 \\
B & $8917-9444$ & 15 & 6 & 1 & 0 & 22 & 31 \\
\hline A & $9445-11085$ & 126 & 91 & 50 & 71 & 338 & 62 \\
B & $9445-11085$ & 19 & 15 & 4 & 2 & 40 & 52 \\
\hline A & $11086-12999$ & 162 & 12 & 74 & 9 & 257 & 36 \\
B & $11086-12999$ & 26 & 9 & 1 & 1 & 37 & 29 \\
\hline A\&B & $13000-14218$ & 150 & 15 & 10 & 0 & 175 & 14 \\
\hline
\end{tabular}

Particular points to note are:

1) The absence of microspots on both IIIa-J and IIIa-F emulsions (plate numbers 8917-9444) which were toned 'in-line'.

2) Both IIIa-J and IIIa-F plates processed in Rapid Fix (Line A) between June 1982 and November 1983 (plate numbers 7793-8916) show a very low level of microspot contamination.

3) IIIa-F plates exposed in 1984-1986 (plate numbers 9445-11085) seem to be particularly badly affected.

4) A significant part of the plate is only affected for those graded D, E or F; the numbers of plates with this level of contamination form less than $10 \%$ of the collection.

5) The most recently affected IIIa-J plates are J 14060 (Dec 1990) which has 'yellow spot' and J 12073 (Aug 1987) with 'gold spot'.

6) The most recent affected IIIa-F plates are R 14131 (Feb 1991) which has 'yellow spot' and R 13417 (Nov 1989) with 'gold spot'.

\section{Selenium Toning}

\subsection{PLATES TONED 'IN-LINE'}

Plates processed in 'Line A' between November 1983 and July 1984 were toned as part of the normal processing routine. None of these plates show any evidence of microspot attack (see also Tables 2 and 3). Selected plates processed after March 1991 have also been toned 'in-line'; none of these plates show any microspots but nor do any others processed at about the same time. 
Figures $1 \mathrm{a}$ and $1 \mathrm{~b}$ show the data from Tables 2 and 3 in graphical form; the vertical lines indicate changes in processing procedures. The line marked ' $x$ ' are plates that are free from spots.

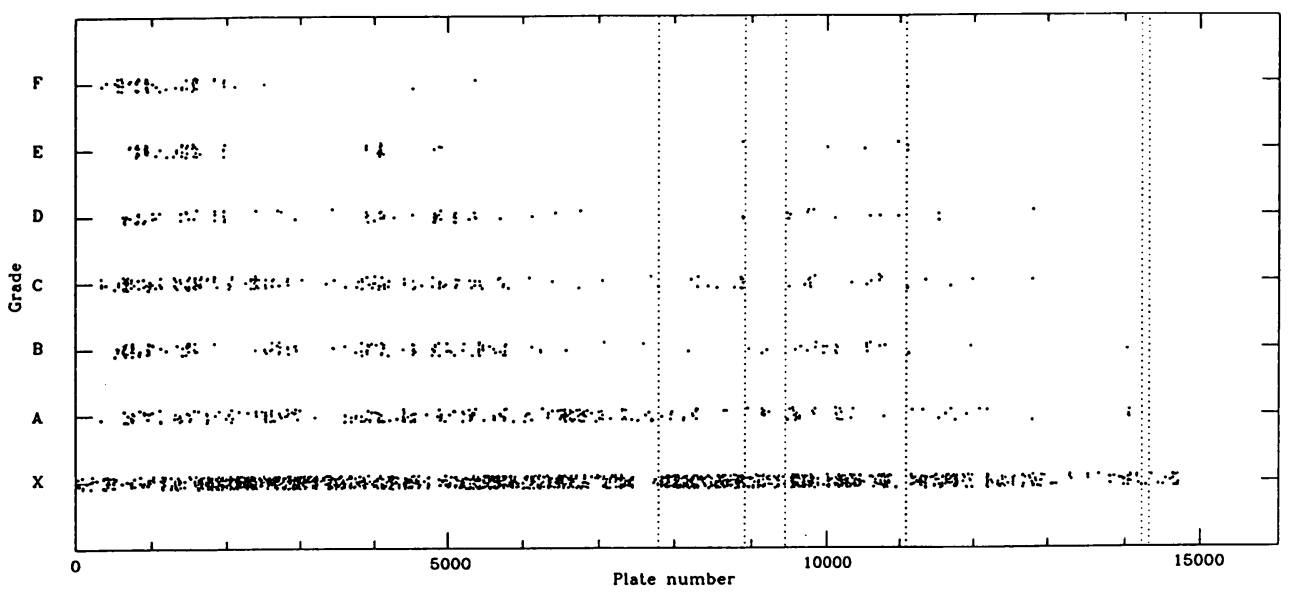

Figure 1a. IIIa-J plates checked for microspots 1990-1993.

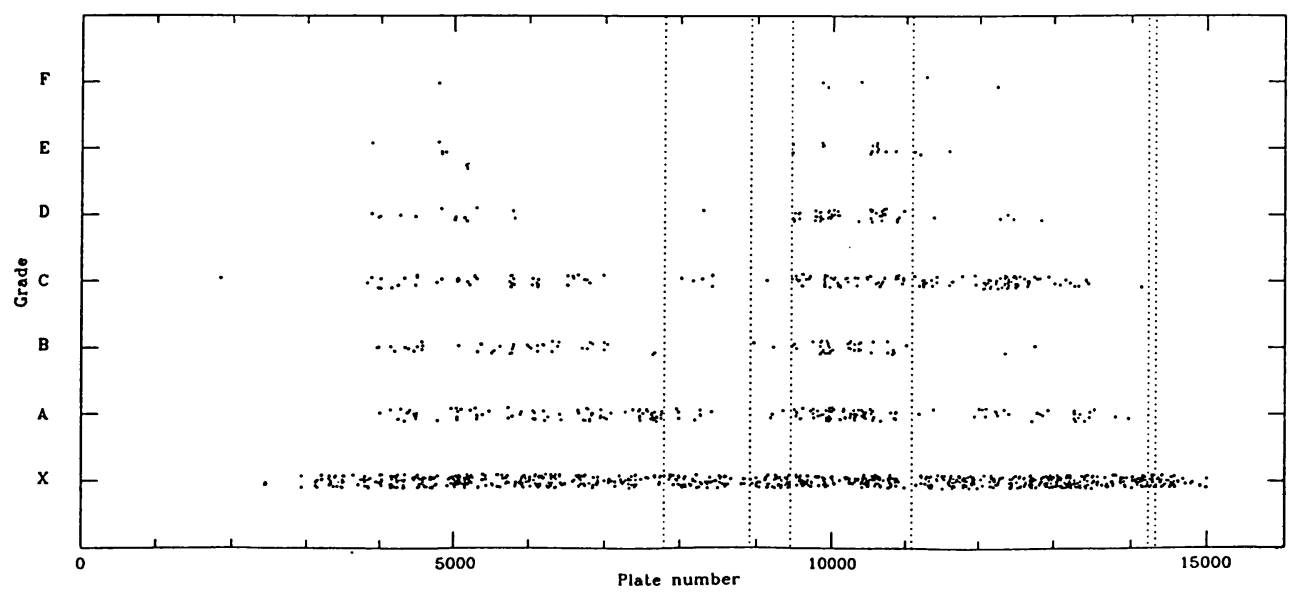

Figure 1b. IIIa-F plates checked for microspots 1990-1993.

\subsection{PLATES TONED AFTER PROCESSING}

A major effort has been made to bathe, in a solution of selenium toner, plates thought to be susceptible to microspot attack. Because the process has been suspected of introducing streaks resembling nebulosity it has been carried out several months (or years) after exposure; this gives time for various studies and measurements to be made on untreated plates.

Previous results have indicated that the treatment has inhibited formation of microspots. 
Altogether, 2768 IIIa-J plates and 1241 IIIa-F plates have been toned, and, of these, 638 IIIa-Js and 1162 IIIa-Fs have been toned since January 1991. The plates are checked for contamination at the time of toning so that any further deterioration can be monitored. Table 4 shows the deterioration, or otherwise, of plates for which two or more checks have been made. For toned plates, the checks have been made at and after the time of toning.

Recently, there has been a suggestion that the toning, although beneficial, does not have an immediate effect. Second estimates of the deterioration of toned plates have therefore been made by excluding plates for which the first 'post-toning' check was made within three months of the date of toning. Unfortunately, there are very few data available for IIIa-F plates. These data are also given in Table 4.

Plates taken between June 1982 and July 1984 were excluded from the data included in Table 4 as they appear not to be badly affected by microspots (see Tables 2 and 3).

Table 4. Deterioration of toned and untoned plates

\begin{tabular}{c|c|r|r|r|r|r|r}
\hline Emulsion & \multirow{2}{*}{$\begin{array}{c}\text { Plate } \\
\text { range }\end{array}$} & \multirow{2}{*}{$\begin{array}{c}\text { Toned/ } \\
\text { Untoned }\end{array}$} & $\begin{array}{c}\text { D } \\
\text { (months) }\end{array}$ & $\begin{array}{c}\text { Sample } \\
\text { size }\end{array}$ & \multicolumn{3}{|c}{ Microspot grade change } \\
\cline { 6 - 8 } & & & & & Same & Worse & Better \\
\hline \hline IIIa-J & $1-7793$ & untoned & 0 & 1539 & $76 \%$ & $22 \%$ & $1 \%$ \\
\hline \hline IIIa-J & $1-7793$ & toned & 0 & 582 & $87 \%$ & $9 \%$ & $4 \%$ \\
\hline \hline IIIa-J & $11-7793$ & toned & 3 & 413 & $91 \%$ & $4 \%$ & $5 \%$ \\
\hline IIIa-J & $9445-13000$ & untoned & 0 & 100 & $90 \%$ & $8 \%$ & $2 \%$ \\
\hline IIIa-J & $9445-13000$ & toned & 0 & 85 & $85 \%$ & $14 \%$ & $0 \%$ \\
\hline IIIa-J & $9445-13000$ & toned & 3 & 1 & $100 \%$ & $0 \%$ & $0 \%$ \\
\hline IIIa-F & $1-7793$ & untoned & 0 & 55 & $76 \%$ & $22 \%$ & $2 \%$ \\
\hline IIIa-F & $1-7793$ & toned & 0 & 118 & $90 \%$ & $10 \%$ & $0 \%$ \\
\hline \hline IIIa-F & $1-7793$ & toned & 3 & 8 & $90 \%$ & $10 \%$ & $0 \%$ \\
\hline \hline IIIa-F & $9445-13000$ & untoned & 0 & 98 & $72 \%$ & $21 \%$ & $6 \%$ \\
\hline IIIa-F & $9445-13000$ & toned & 0 & 226 & $82 \%$ & $16 \%$ & $2 \%$ \\
\hline \hline IIIa-F & $9445-13000$ & toned & 3 & 18 & $88 \%$ & $6 \%$ & $6 \%$ \\
\hline Nof & & & & & & \\
\hline
\end{tabular}

\section{Notes:}

1) ' $D$ ' shows the time elapsed between the date of toning and the first check.

2) The number of plates which have 'improved' gives an indication of the grading errors inherent in the inspection process.

Points to note:

1) The table shows clearly that plates do deteriorate after toning although the rate of deterioration is generally lower than for untoned plates.

2) The limited data available suggest that the deterioration of toned plates after three months from the data of toning is reduced to the level of the grading inconsistencies. 


\section{Conclusions}

1) IIIa- emulsions taken with the UK $1.2 \mathrm{~m}$ Schmidt Telescope continue to show evidence of microspot attack.

2) Plates exposed between June 1982 and October 1983 and processed in Rapid Fix show a very low level of microspot contamination.

3) The non-reflective 'yellow spot' seems to become reflective in time.

4) Plates which were bathed in selenium toner as part of the normal processing procedure appear to be immune to microspots.

5) A post-processing bathe in selenium toner offers protection against the initiation and growth of spot formation. However, there is evidence of some deterioration during the first few months after treatment.

6) No conclusion can yet be reached about the efficacy of the introduction of potassium iodide into the fixer.

\section{Acknowledgements}

We wish to thank Mrs Rosemary Smith for her help with the plate check and several 'work experience' students who typed the data onto the computer.

\section{References}

Tritton, S.B., Morgan, D.H. and Cranston, M.R., 1992. 'Astronomical Photography 1990', ed. J.L. Heudier, Universite de Nice-Sophia-Antipolis, p.10. 